\title{
FORMULATION OF ONCE A DAY CONTROLLED RELEASE TABLET OF INDOMETHACIN BASED ON HPMC-MANNITOL
}

\author{
Roshan Pradhan, Uttam Budhathoki, Panna Thapa* \\ Department of Pharmacy \\ Kathmandu University, Dhulikhel, Kavre, GPO Box 6250, Kathmandu, Nepal. \\ *Corresponding author: pannathapa @ku.edu.np \\ Received 6 September; Revised 21 September
}

\begin{abstract}
A hydroxypropyl methylcellulose (HPMC K4M, HPMC K15M, and HPMC K100M) matrix tablet containing Indomethacin along with mannitol was formulated as a function of HPMC viscosity, and was compared with the commercial products. The release characteristics of the matrix tablet were investigated in the intestinal fluid, $6.8 \mathrm{pH}$ phosphate buffer for 12 hours. The formulated products and two marketed products as reference sample were studied for its different physicochemical parameters and in vitro dissolution studies. It was found that the drug release profile decreases with increase in viscosity of polymer and, with increase polymer level in the formulations. Matrix tablets formulated employing Drug:HPMC K15M:mannitol::1:0.25:1 and Drug:HPMC K15M:mannitol::1:0.25:2 gave slow release of indomethacin spread over 12 hours and their dissolution profiles were compared with the Indian marketed product. The dissolution profiles of both the formulations were similar to the dissolution profile of the marketed product, the similarity factor being 74.59 and 68.04 respectively. The dissolution profiles of formulations containing same viscosity grade of HPMC in remarkably different concentrations and different viscosity grade of HPMC in same concentrations were different.
\end{abstract}

Key words: Indomethacin, Controlled release, Hydroxypropyl methyl cellulose, Mannitol, Dissolution.

\section{INTRODUCTION}

The oral route of drug delivery is the most popular, desirable and preferred method of administering therapeutic agents for systemic effects because it is natural, convenient for the patient, and cost effective to manufacturing process. One of the most common approaches used for prolonging and controlling the rate of drug release is to incorporate a drug in hydrophilic colloid matrix such as hydroxypropylcellulose, hydroxypropylmethylcellulose (HPMC), carbopol, methylcellulose, alginates and gelatin. The mechanism and kinetics of release of the drug incorporated in these polymer matrices is dependent on the type and amount of polymer as well as on the physicochemical properties of the drug. Generally drug release from these matrices follow penetration of fluid, followed by dissolution of the drug particles and diffusion through fluid filled pores (Collett and Moreton, 2002). The diffusion of a drug through a matrix is the rate-limiting step.

In hydrophilic polymer matrix system, zero-order release kinetics can be maintained if the polymer swells at a constant rate, maintaining a constant surface area and the diffusion of the drug is comparatively rapid (Weinberger and Hendeles,1996). In addition to matrix system, 
reservoir or membrane-controlled and osmotic controlled release systems have also been used for prolonging and controlling the drug release rate (Singh and Kim, 2002).

However, the variable absorbing surfaces over the length of the GI tract adds constraint to the design of oral dosage forms. Moreover, the stomach emptying period varies from person to person. These factors collectively introduce considerable variability in the performance of oral controlled delivery systems (Kumar and Kumar 2001)

\section{Objectives}

1. To formulate and develop methods for matrix tablet of Indomethacin using different grades of hydrophilic polymer (HPMC).

2. To determine the physiochemical parameters such as diameter, thickness and weight variation of the formulations.

3. To study the release profile of the formulation using various drug polymer ratios.

4. To compare dissolution profile of the formulated product with marketed SR product.

5. To evaluate drug release profile with respect to mathematical modeling.

\section{MATERIAL AND METHODS}

The drug molecule Indomethacin (Manufactured by Shijiazhuang Pharmaceutical Group, China Mfg:3/2005 Exp:3/2010) was received as a gift sample from Omnica Laboratories Pvt. Ltd, Chittapole VDC, Bhaktapur. HPMC K4M, HPMC K15M, HPMC K100M (Manufactured by Colorcon Asia Pvt .Ltd. ) and mannitol (Manufactured by Qualigens Fine Chemicals) was obtained from Kathmandu University was used.

Similarly Dibasic Calcium Phosphate, Magnesium stearate, Talcum, Sodium Starch Glycolate were received as gift sample from Omnica Laboratories Pvt. Ltd and Lacto Press (spray dried lactose) was received as gift sample from Vijay deep Pharmaceuticals Pvt. Ltd. Indocap SR and Inar of Jagsonpal Pharmaceuticals Ltd, India and Hukum Pharmaceuticals Pvt.Ltd, Nepal respectively were used as a marketed product. Distilled water prepared in department of pharmacy was used throughout the study.

\section{Formulation of immediate releasing granules}

The drug containing $10 \mathrm{mg}$ of indomethacin was milled and passed through 200 mesh size sieve. Other excipients were passed through 40 mesh. The drug along with the additives was thoroughly mixed in polybag for 20 minutes.

\section{Formulation of slow releasing matrix granules}

Matrix granules were prepared by Wet granulation method (Non-aqueous binding). The drug containing $65 \mathrm{mg}$ of indomethacin was milled and passed through $200 \mathrm{mesh}$ and other additives (polymer and diluents) except magnesium stearate and talc were passed through 40 mesh sieve and thoroughly mixed in polybag for 20 minutes followed by the addition of binding agent to prepare dough mass. Dough mass was passed through 10 mesh sieve to prepare the granules and left 24 hours for air-drying. After 24 hours, again granules were passed through 20 mesh sieve and mixed with magnesium stearate and talc (previously passed through 60 mesh sieve) and shaked for 5 minutes.

\section{Preparation of Matrix Tablet}

An immediate releasing granules containing $10 \mathrm{mg}$ of indomethacin was fed to the $10 \mathrm{~mm}$ die of the 10-station rotary tablet compression machine (Rimek Mini Press-1) followed by feeding slow 
releasing granules containing $65 \mathrm{mg}$ of indomethacin. Therefore $300 \mathrm{mg}$ matrix tablet was obtained containing $75 \mathrm{mg}$ indomethacin. The compositions are given in Table 1.

Table 1. Composition of the formulations prepared.

\begin{tabular}{|c|c|c|c|c|c|c|c|c|c|c|c|c|c|c|c|c|c|c|}
\hline \multicolumn{19}{|c|}{ Indomethacin immediate releasing Granules } \\
\hline \multicolumn{2}{|c|}{ Formulations } & \multirow{2}{*}{$\begin{array}{c}\text { ICR-1 } \\
\begin{array}{c}Q t / t a b \\
(\mathrm{mg})\end{array}\end{array}$} & \multirow{2}{*}{$\begin{array}{c}\text { ICR-2 } \\
\begin{array}{c}\text { Qt/tab } \\
(\mathrm{mg})\end{array} \\
\end{array}$} & \multirow{2}{*}{$\begin{array}{c}\text { ICR-3 } \\
\begin{array}{c}\text { Qt/tab } \\
(\mathrm{mg})\end{array} \\
\end{array}$} & \multirow{2}{*}{\begin{tabular}{|c} 
ICR-4 \\
$\begin{array}{c}\text { Qt/tab } \\
(\mathrm{mg})\end{array}$ \\
\end{tabular}} & \multirow{2}{*}{$\begin{array}{c}\text { ICR-5 } \\
\begin{array}{c}\text { Qt/tab } \\
(\mathrm{mg})\end{array}\end{array}$} & \multirow{2}{*}{\begin{tabular}{|c|} 
ICR-6 \\
$\begin{array}{c}\text { Qt/tab } \\
(\mathrm{mg})\end{array}$
\end{tabular}} & \multirow{2}{*}{$\begin{array}{c}\text { ICR-7 } \\
\begin{array}{l}\text { t/tab } \\
(\mathrm{mg})\end{array}\end{array}$} & \multirow{2}{*}{$\begin{array}{c}\text { ICR-8 } \\
\begin{array}{c}\text { Qt/tab } \\
(\mathrm{mg})\end{array}\end{array}$} & \multirow{2}{*}{$\begin{array}{c}\text { ICR-9 } \\
\begin{array}{c}\text { Qt/tab } \\
(\mathrm{mg})\end{array}\end{array}$} & \multirow{2}{*}{$\begin{array}{c}\text { ICR- } \\
10\end{array}$} & \multirow{2}{*}{\begin{tabular}{|c|} 
ICR- \\
11
\end{tabular}} & \multirow{2}{*}{$\begin{array}{c}\text { ICR- } \\
12\end{array}$} & \multirow{2}{*}{\begin{tabular}{|c}
$\begin{array}{c}\text { ICR- } \\
13\end{array}$ \\
$\begin{array}{c}\text { Qt/tab } \\
(\mathrm{mg})\end{array}$ \\
\end{tabular}} & \multirow{2}{*}{$\begin{array}{c}\begin{array}{c}\text { ICR- } \\
14\end{array} \\
\begin{array}{c}\text { Qt/tab } \\
(\mathrm{mg})\end{array}\end{array}$} & \multirow{2}{*}{$\begin{array}{c}\begin{array}{c}\text { ICR- } \\
15\end{array} \\
\text { Qt/tab } \\
(\mathrm{mg})\end{array}$} & \multirow{2}{*}{$\begin{array}{c}\text { ICR- } \\
16 \\
Q t / t a b \\
(\mathrm{mg})\end{array}$} & \multirow{2}{*}{$\begin{array}{c}\begin{array}{c}\text { ICR- } \\
17\end{array} \\
\text { Qt/tab } \\
(\mathrm{mg})\end{array}$} \\
\hline$S . N$ & Ingredients & & & & & & & & & & & & & & & & & \\
\hline 1 & $\begin{array}{l}\text { Indomethacin } \\
\text { IP }\end{array}$ & --- & --- & 10 & 10 & 10 & 10 & 10 & 10 & 10 & 10 & 10 & 10 & 10 & 10 & 10 & 10 & 10 \\
\hline 2 & $\begin{array}{l}\text { Dibasic Calcium } \\
\text { Phosphate }\end{array}$ & --- & --- & 86 & 86 & 86 & 86 & 86 & 86 & 86 & 86 & 86 & 36 & 11 & 36 & 11 & 36 & 11 \\
\hline 3 & $\begin{array}{l}\text { Sodium Starch } \\
\text { Glycolate IP }\end{array}$ & --- & --- & 4 & 4 & 4 & 4 & 4 & 4 & 4 & 4 & 4 & 4 & 4 & 4 & 4 & 4 & 4 \\
\hline \multicolumn{19}{|c|}{ Indomethacin slow releasing Granules } \\
\hline 1 & \begin{tabular}{|l|} 
Indomethacin \\
IP
\end{tabular} & 75 & 75 & 65 & 65 & 65 & 65 & 65 & 65 & 65 & 65 & 65 & 65 & 65 & 65 & 65 & 65 & 65 \\
\hline 2 & НРМС К4M & --- & --- & 75 & 37.5 & 18.75 & --. & --. & --.- & --- & --- & --- & 37.5 & 37.5 & 18.75 & 18.75 & --- & --- \\
\hline 3 & HРMC К15M & --- & --- & $-\cdots$ & --- & --- & 75 & 37.5 & 18.75 & --- & 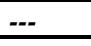 & --- & --- & --- & --- & --- & 18.75 & 18.75 \\
\hline 4 & НРМС К100М & --- & --- & --- & --- & --- & --- & --- & --- & 75 & 37.5 & 18.75 & --- & --- & --- & --- & --- & --- \\
\hline 5 & Mannitol & 75 & 150 & $-\cdots$ & $\begin{array}{ll}-- \\
\end{array}$ & --- & $\begin{array}{ll}-- \\
\end{array}$ & $-\cdots$ & $-\cdots$ & $-\cdots$ & $\begin{array}{ll}-- \\
\end{array}$ & --- & 75 & 150 & 75 & 150 & 75 & 150 \\
\hline 6 & $\begin{array}{l}\text { Dibasic Calcium } \\
\text { Phosphate }\end{array}$ & 105 & 30 & 15 & 52.5 & 71.25 & 15 & 52.5 & 71.25 & 15 & 52.5 & 71.25 & 27.5 & --- & 46.25 & 18.75 & 46.25 & 18.75 \\
\hline 7 & Lacto Press & 30 & 30 & 30 & 30 & 30 & 30 & 30 & 30 & 30 & 30 & 30 & 30 & 7.5 & 30 & 7.5 & 30 & 7.5 \\
\hline 8 & Talcum & 9 & 9 & 9 & 9 & 9 & 9 & 9 & 9 & 9 & 9 & 9 & 9 & 9 & 9 & 9 & 9 & 9 \\
\hline 9 & $\begin{array}{l}\text { Magnesium } \\
\text { Stearate }\end{array}$ & 6 & 6 & 6 & 6 & 6 & 6 & 6 & 6 & 6 & 6 & 6 & 6 & 6 & 6 & 6 & 6 & 6 \\
\hline 10 & Alcohol & --- & --- & q.s & $q . s$ & $q . s$ & $q . s$ & $q . s$ & $q . s$ & q.s & $q . s$ & q.s & $q . s$ & q.s & $q . s$ & $q . s$ & $q . s$ & $q . s$ \\
\hline \multicolumn{2}{|c|}{ Total } & 300 & 300 & 300 & 300 & 300 & 300 & 300 & 300 & 300 & 300 & 300 & 300 & 300 & 300 & 300 & 300 & 300 \\
\hline
\end{tabular}

\section{Characterization of matrix formulations}

1. Weight Variation: For the determination of weight variation of each batch, tablets were randomly sampled and individual weight of 20 tablets was taken in analytical balance. Mean \pm standard deviation (s.d) was calculated.

2. Thickness: From randomly sampled tablets, thickness of 10 tablets was measured individually using digital vernier caliper. Then mean \pm s.d was calculated.

3. Diameter Variation: Diameters of 10 tablets from each batch were checked using digital vernier caliper. Then mean \pm SD was calculated.

4. Hardness: Hardness of 10 tablets was measured individually using pre-calibrated digital hardness tester. Then mean \pm SD was calculated.

5. Friability: 20 tablets were weighted in a balance having readability of $1 \mathrm{mg}$. These tablets were transformed into a friabilator set 100 revolutions. After the completion of revolution dust was removed completely, weighted again in the same balance and percentage loss was calculated.

6. Assay: 20 tablets were weighed and its average weight was taken which was crushed in motor and pestle. The powder weight equivalent to single tablets i.e. $75 \mathrm{mg}$ was dissolved in $10 \mathrm{ml}$ water in a $100 \mathrm{ml}$ volumetric flask and allowed to stand for 10 minutes. To that $75 \mathrm{ml}$ of methanol was added initially followed by addition of sufficient methanol to produce $100 \mathrm{ml}$ which was then filtered through whatmann filter paper. $5 \mathrm{ml}$ of this resulting solution was further 
diluted to $50 \mathrm{ml}$ with $7.2 \mathrm{pH}$ phosphate buffer: methanol (1:1). Again $5 \mathrm{ml}$ was diluted to $50 \mathrm{ml}$ by the same solvent. The absorbance of each of the standard and sample solution were taken in UV-visible spectrophotometer at $320 \mathrm{~nm}$ using equal volumes of $7.2 \mathrm{pH}$ phosphate buffer and methanol as blank.

\section{In-Vitro Dissolution studies}

In-Vitro dissolution study of all the formulated tablets and market sample was carried out in USP dissolution apparatus II (paddle) at $37 \pm 2^{\circ} \mathrm{C}$ and $75 \mathrm{rpm} 750 \mathrm{ml} 6.8 \mathrm{pH}$ phosphate buffer. The time of tablet addition was noted and $10 \mathrm{ml}$ of sample was withdrawn at 1, 2, 4, 6,8 and 12 hour. $10 \mathrm{ml}$ of dissolution medium was replaced into dissolution vessel after each sampling in order to maintain sink condition. USP Dissolution Test 3 of Indomethacin Extended-release Capsules. The absorbance of each of the standard and sample solution were taken in UV-visible spectrophotometer at $318 \mathrm{~nm}$ using $6.8 \mathrm{pH}$ phosphate buffer as blank.

\section{Mathematical Modeling of Drug Release Profile [5]}

The cumulative amount of indomethacin release from the formulated tablets at different time intervals were fitted to zero order kinetics, first order kinetics, Higuchi model and Koremeyer Peppas model to characterize mechanism of drug release.

\section{Zero Order Kinetic}

It describes the system in which the drug release rate is independent of its concentration.

$$
Q_{t}=Q_{o}+K_{o} t
$$

Where

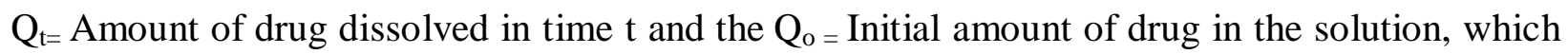
is often zero and $\mathrm{K}_{\mathrm{o}}$ is the zero order release constant.

If the zero order drug release kinetic is obeyed, then a plot of $Q_{t}$ versus $t$ will give a straight line with a slope of Ko and an intercept at zero.

\section{First Order Kinetic}

It describes the drug release from the systems in which the release rate is concentration dependent.

$$
\log Q_{t}=\log Q_{o}+k t / 2.303
$$

Where $\mathrm{Q}_{\mathrm{t}}$ is the amount of drug released in time $\mathrm{t}$. $\mathrm{Q}_{\mathrm{o}}$ is the initial amount of drug in the solution and $\mathrm{k}$ is the first order release constant

If the first order drug release kinetic is obeyed, then a plot of $\log \left(\mathrm{Q}_{\mathrm{o}}-\mathrm{Q}_{\mathrm{t}}\right)$ versus $\mathrm{t}$ will be straight line with a slope of $\mathrm{kt} / 2.303$ and an intercept at $\mathrm{t}=0$ of $\log \mathrm{Q}_{\mathrm{o}}$

\section{Higuchi Model}

It describes the fraction of drug release from a matrix is proportional to square root of time.

$$
M t / M \infty=k_{H} t^{1 / 2}
$$

Where Mt and $\mathrm{M} \infty$ are cumulative amounts of drug release at time $\mathrm{t}$ and infinite time, and $\mathrm{k}_{\mathrm{H}}$ is the Higuchi dissolution constant reflection formulation characteristics. If the Higuchi model of drug release (i.e. Fickian diffusion) is obeyed, then a plot of $\mathrm{Mt} / \mathrm{M} \infty$ versus $\mathrm{t}^{1 / 2}$ will be straight line with slope of $\mathrm{k}_{\mathrm{H}}$. 


\section{Korsmeyer-Peppas model (Power Law)}

The power law describes the drug release from the polymeric system in which release deviates from Fickian diffusion, as expressed in following equation.

$$
\begin{aligned}
& M t / M \infty=k t^{n} \\
& \log [M t / M \infty]=\log k+n \log t
\end{aligned}
$$

Where $\mathrm{Mt}$ and $\mathrm{M} \infty$ are cumulative amounts of drug release at time $\mathrm{t}$ and infinite time (i.e.fraction of drug release at time $\mathrm{t}$ ), $\mathrm{k}$ is the constant incorporating structural and geometrical characteristics of CR device, and $\mathrm{n}$ is a diffusional release exponent indicative of the mechanism of drug release for drug dissolution. To characterize the release mechanism, the dissolution data $\{\mathrm{Mt} / \mathrm{M} \infty<0.6\}$ are evaluated. A plot of $\log \{\mathrm{Mt} / \mathrm{M} \infty\}$ versus $\log \mathrm{t}$ will be linear with slope of $\mathrm{n}$ and intercept gives the value of $\log \mathrm{k}$. Antilog of $\log \mathrm{k}$ gives the value of $\mathrm{k}$.

Peepas used the $\mathrm{n}$ value in order to characterize different release mechanisms as shown in the table below

This equation has two distinct physical realistic meaning in the two special cases of $n=0.5$ (indicating diffusion- controlled drug release) and $n=1$. $n$ between 0.5 and 1 can be regarded as an indicator for the superposition of both phenomena (anomalous transport).

It has to be kept in mind that the two extreme values for the exponent n, 0.5 and 1.0 are only valid for slab geometry. For spheres and cylinders different values have been derived.

\section{Statistical analysis}

Linear regression analysis was performed to compare the mechanism of drug release rate of the different formulations. Similarity and difference factors were used to compare dissolution profiles between the formulations and each with the marketed product (Costa and Lobo, 2001)

\section{RESULTS AND DISCUSSION Physicochemical Properties}

Almost all the formulated products lied within the pharmacopoeial requirement within $\pm 5 \%$ for weight variation. Other physiochemical properties such as, hardness, thickness, diameter, friability and assay results were determined and presented in Table 2.

Hardness of the formulated products were found in between $41 \mathrm{~N}$ and $158 \mathrm{~N}$. The thickness and diameter were found in the range of 2.30 to $3.20 \mathrm{~mm}$ and 9.94 to $10.03 \mathrm{~mm}$ respectively. The friability was found in the range of $0.055 \%$ and $0.455 \%$. The assay values of the formulated tablets were found in between $95.806 \%$ and $100.372 \%$. 
Table 2: Hardness, Thickness, Diameter, Friability and Assay of the matrix tablets prepared

\begin{tabular}{|c|c|c|c|c|c|}
\hline Formulations & Hardness $(N)$ & Thickness (mm) & Diameter (mm) & Friability (\%) & Assay (\%) \\
\hline & \pm s.d $(n=10)$ & $\pm s . d(n=10)$ & \pm s.d $(n=10)$ & & \pm s.d $(n=3)$ \\
\hline ICR 1 & $48 \pm 3.88$ & $2.91 \pm 0.21$ & $9.99 \pm 0.02$ & 0.45 & $99.361 \pm 0.17$ \\
\hline$I C R 2$ & $49 \pm 6.02$ & 3.02 \pm 0.05 & $9.99 \pm 0.02$ & 0.40 & $99.683 \pm 0.61$ \\
\hline ICR 3 & $109 \pm 3.88$ & $2.98 \pm 0.03$ & $\mathbf{1 0 . 0 0} \pm 0.02$ & 0.22 & 98.391 \pm 0.17 \\
\hline$I C R 4$ & $107 \pm 3.26$ & 3.07 \pm 0.05 & $9.99 \pm 0.02$ & 0.21 & $98.477 \pm 0.47$ \\
\hline ICR 5 & $71 \pm 4.14$ & $\mathbf{3 . 1 3} \pm 0.01$ & $10.00 \pm 0.03$ & 0.13 & $97.950 \pm 0.17$ \\
\hline ICR 6 & $137 \pm 7.04$ & 3.01 \pm 0.07 & $9.98 \pm 0.02$ & 0.29 & $98.424 \pm 0.20$ \\
\hline ICR 7 & $138 \pm 4.81$ & $\mathbf{3 . 1 3} \pm 0.01$ & $\mathbf{1 0 . 0 0} \pm 0.01$ & 0.22 & $97.486 \pm 0.18$ \\
\hline ICR 8 & $106 \pm 4.29$ & 3.01 \pm 0.04 & $\mathbf{1 0 . 0 0} \pm 0.01$ & 0.12 & $97.787 \pm 0.38$ \\
\hline ICR 9 & $113 \pm 7.34$ & $\mathbf{3 . 0 6} \pm 0.06$ & $\mathbf{1 0 . 0 0} \pm 0.02$ & 0.23 & $97.377 \pm 0.12$ \\
\hline ICR 10 & $149 \pm 6.19$ & $3.04 \pm 0.05$ & $9.97 \pm 0.02$ & 0.19 & $\mathbf{9 7 . 8 3 3} \pm 0.17$ \\
\hline ICR 11 & $143 \pm 2.36$ & $3.12 \pm 0.01$ & $\mathbf{1 0 . 0 0} \pm 0.02$ & 0.11 & $96.695 \pm 0.79$ \\
\hline ICR 12 & $\mathbf{1 0 6} \pm 4.21$ & $2.98 \pm 0.01$ & $\mathbf{1 0 . 0 2} \pm 0.01$ & 0.15 & $99.000 \pm 0.39$ \\
\hline ICR 13 & $118 \pm 3.90$ & $\mathbf{3 . 1 3} \pm 0.05$ & $\mathbf{1 0 . 0 1} \pm 0.02$ & 0.09 & $98.199 \pm 0.28$ \\
\hline ICR 14 & $\mathbf{1 0 5} \pm 2.74$ & $\mathbf{3 . 1 3} \pm 0.02$ & $\mathbf{1 0 . 0 2} \pm 0.01$ & 0.17 & $98.016 \pm 0.19$ \\
\hline ICR 15 & $\mathbf{1 0 2} \pm 1.91$ & $\mathbf{3 . 0 1} \pm 0.05$ & $\mathbf{1 0 . 0 1} \pm 0.02$ & 0.05 & $98.006 \pm 0.28$ \\
\hline ICR 16 & $\mathbf{1 0 7} \pm 3.83$ & $3.12 \pm 0.02$ & $\mathbf{1 0 . 0 0} \pm 0.02$ & 0.13 & $97.661 \pm 0.16$ \\
\hline ICR 17 & $\mathbf{1 0 5} \pm 2.72$ & $\mathbf{3 . 1 3} \pm 0.02$ & $9.99 \pm 0.02$ & 0.06 & $98.417 \pm 0.15$ \\
\hline$J M S$ & \multicolumn{4}{|l|}{ Not Applicable } & $98.993 \pm 0.41$ \\
\hline HMS & \multicolumn{4}{|l|}{ Not Applicable } & $97.927 \pm 0.36$ \\
\hline
\end{tabular}




\section{In-Vitro Dissolution studies}

The in-vitro dissolution characteristics of different formulation were carried out in $6.8 \mathrm{pH}$ phosphate buffer. The percentage of drug released from the marketed and formulated tablets are given in Table 3.

Table 3. Dissolution profile of formulated Indomethacin tablets prepared and Marketed products

\begin{tabular}{|c|c|c|c|c|c|c|c|}
\hline \multirow{2}{*}{$\begin{array}{l}\text { Formulation } \\
\text { Code }\end{array}$} & \multicolumn{6}{|c|}{ Time (USP24 Test 3 Requirement) } & \multirow[b]{2}{*}{ Remarks } \\
\hline & $\begin{array}{l}1 \text { Hour } \\
(15-40)\end{array}$ & $\begin{array}{l}2 \text { Hour } \\
(35-55)\end{array}$ & $\begin{array}{l}4 \text { Hour } \\
(55-75)\end{array}$ & $\begin{array}{l}6 \text { Hour } \\
(65-85)\end{array}$ & 8 Hour & 12 Hour (75) & \\
\hline ICR 1 & 44.767 & 95.483 & -- & -- & -- & -- & \\
\hline ICR 2 & 35.623 & 69.566 & 97.937 & --- & -- & -- & \\
\hline ICR 3 & 17.623 & 26.917 & 42.565 & 59.927 & 64.238 & $\overline{--}$ & \\
\hline ICR 4 & 30.146 & 39.637 & 58.415 & 81.799 & 87.071 & $\overline{--}$ & \\
\hline ICR 5 & 32.684 & 39.118 & 69.975 & 83.380 & 93.510 & -- & \\
\hline ICR 6 & 20.589 & 25.722 & 39.845 & 58.430 & 67.596 & -- & \\
\hline ICR 7 & 29.378 & 38.426 & 58.530 & 63.845 & 76.517 & -- & \\
\hline ICR 8 & 34.674 & 41.777 & 61.308 & 74.430 & 81.583 & 88.829 & \\
\hline ICR 9 & 16.873 & 23.851 & 35.526 & 42.505 & 56.060 & -- & \\
\hline ICR 10 & 20.833 & 31.266 & 41.187 & 52.618 & 62.246 & $\overline{--}$ & \\
\hline ICR 11 & 24.015 & 38.112 & 53.736 & 68.000 & 73.631 & -- & \\
\hline ICR 12 & 24.598 & 37.279 & 56.845 & 74.038 & 86.039 & -- & \\
\hline ICR 13 & 23.439 & 38.512 & 54.289 & 73.574 & 84.938 & -- & \\
\hline ICR 14 & 28.747 & 38.011 & 64.443 & 80.335 & 93.047 & -- & \\
\hline ICR 15 & 25.507 & 36.128 & 61.795 & 78.426 & 90.826 & -- & \\
\hline ICR 16 & 25.401 & 38.967 & 59.172 & 71.201 & 79.687 & 86.370 & \\
\hline ICR 17 & 24.408 & 37.363 & 57.651 & 69.632 & 79.544 & 85.387 & \\
\hline$J M S$ & $\begin{array}{l}25.464 \\
\pm 3.030\end{array}$ & $\begin{array}{l}44.183 \\
\pm 2.968\end{array}$ & $\begin{array}{l}60.487 \\
\pm 3.134\end{array}$ & $\begin{array}{r}72.996 \\
\pm 3.002\end{array}$ & $\begin{array}{l}81.550 \\
\pm 2.951\end{array}$ & $89.737 \pm 2.019$ & Capsule \\
\hline HMS & $\begin{array}{l}32.727 \\
\pm 5.362\end{array}$ & $\begin{array}{l}63.745 \\
\pm 7.262\end{array}$ & $\begin{array}{l}68.149 \\
\pm 4.458\end{array}$ & $\begin{array}{l}79.685 \\
\pm 2.219\end{array}$ & $\begin{array}{l}84.379 \\
\pm 4.900\end{array}$ & $90.168 \pm 2.186$ & Capsule \\
\hline
\end{tabular}

\section{Dissolution from formulated tablets}

\section{Effect of drug: polymer ratio}

Drug release from the swellable matrix tablet is based on the glassy-rubbery transition of the polymer, which is due to the penetration of the water into the matrix system. The primary factor of the drug release control is the interaction between the water, drug and polymer. Beside this some other variables also play a role in the release profile like drug loading, drug: polymer ratio, viscosity of polymer (molecular weight) and compression force (Elkheshen, 2001).

Considering formulations ICR 1 and ICR 2 incorporating drug and mannitol alone in the ratio 1:1 and 1:2 respectively, the complete drug release was achieved within 2 to 4 hours. Among the other formulations containing HPMC K4M, HPMC K15M and HPMC K100M alone (from ICR 3 to ICR 11) in different drug polymer ratios, none of the formulations except ICR 8 having drug polymer ratio 1:0.25 showed similar drug release profile to that of the Indian marketed product.

According to Ford, the most important factor affecting the rate of release of drug concentration from HPMC matrices was drug: polymer ratio. An increase in the polymer concentration causes an increase in the viscosity of the gel. This could cause a decrease in effective diffusion 
coefficient of the drug and thereby reducing in the drug release. In the present formulations too it was realized that the release profile decreased with increasing drug: polymer ratio.

Drug release profile of formulated tablets containing HPMC K4M, HPMC K15M and HPMC $\mathrm{K} 100 \mathrm{M}$ alone in different drug polymer ratio is shown in Figures 1, 2 and 3 respectively.

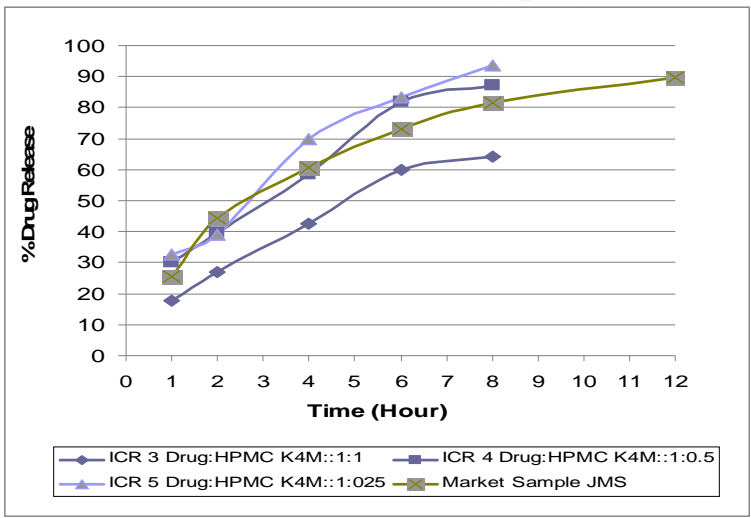

Figure 1. Drug release profile of formulated tablets containing HPMC K4 M at different ratios.

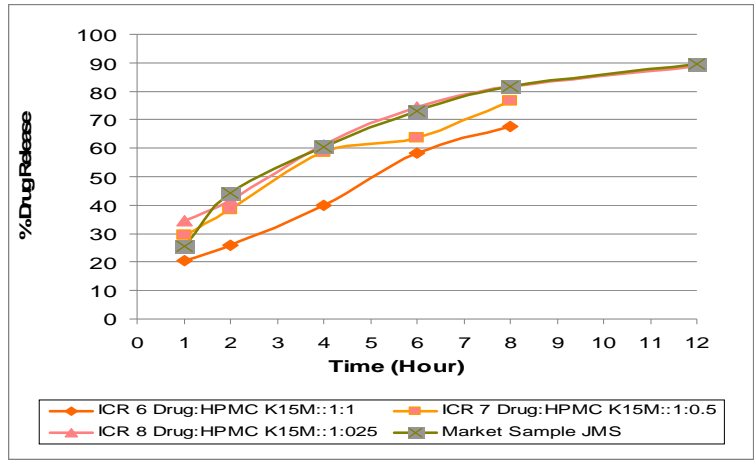

Figure 2. Drug release profile of formulated tablets containing HPMC K15 M at different ratios.

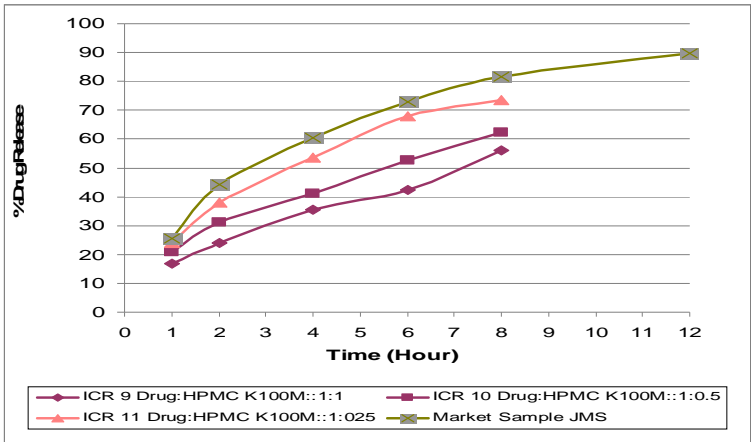

Figure 3. Drug release profile of formulated tablets containing HPMC K100M at different ratios.

Comparing formulations ICR 12, ICR 13,ICR 14, ICR 15, ICR 16 and ICR 17 all of which contained both HPMC and mannitol, ICR 16 and ICR 17 having drug: polymer: mannitol ratio 1:0.25:1 and 1:0.25:2 respectively showed similar drug release profile to that of the Indian marketed product. The drug release profile of these formulations are shown in Figures 4 and 5, respectively. 


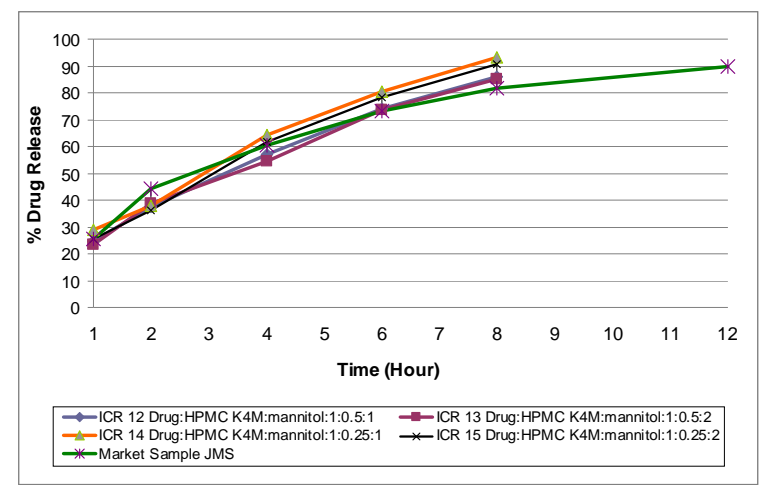

Figure 4. Drug release profile of formulated tablets containing HPMC K4M and mannitol at different ratios.

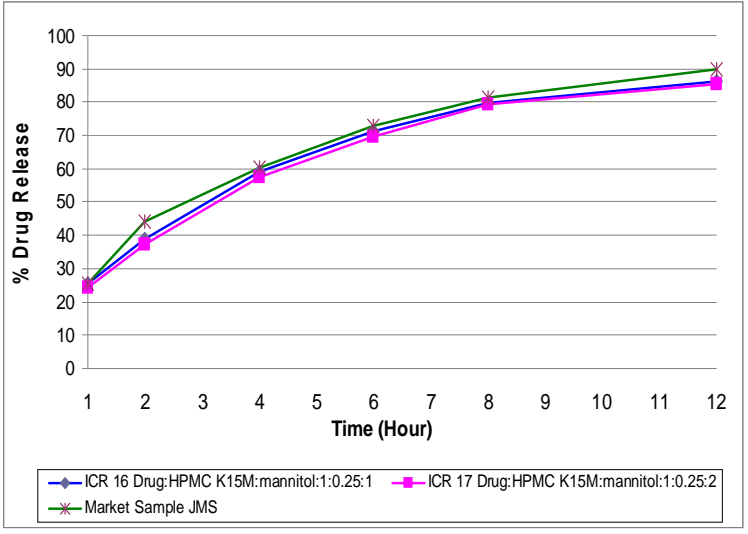

Figure 5. Drug release profile of formulated tablets containing HPMC K15M and mannitol at different ratios.

\section{Effect of the different viscosity of the HPMC}

It is suggested that the hydrophilic polymer such as HPMC when comes in contact with the water, it absorbs water and swells to form a gel layer which serves as a barrier to drug diffusion. The drug release process from a HPMC matrix involves water penetration into the dry matrix, hydration and gelation of the polymer, dissolution of the drug and diffusion of the dissolved drug through the resultant gel layer. Since the movement of the drug through the matrix system is predominantly diffusion controlled, it may be expected from Stokes-Einstein equation, which states that the process will be slower in the more viscous layer (Elkheshen, 2001).

Regarding drug release profiles of the formulated tablets, it was observed that there was a gradual decrease in the rate of release of the drug from the polymer (HPMC) with increase in the viscosity as shown in Figures 6, 7 and 8 respectively.

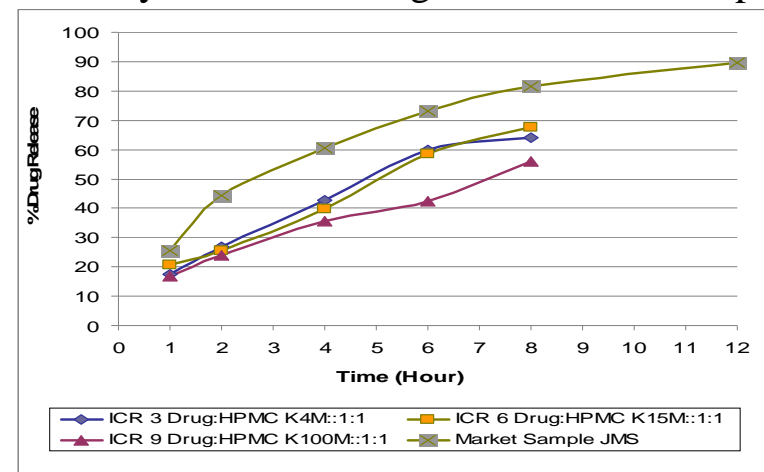

Figure 6. Dissolution profile of formulated products with different grades of HPMC at drug: polymer ratio 1:1. 


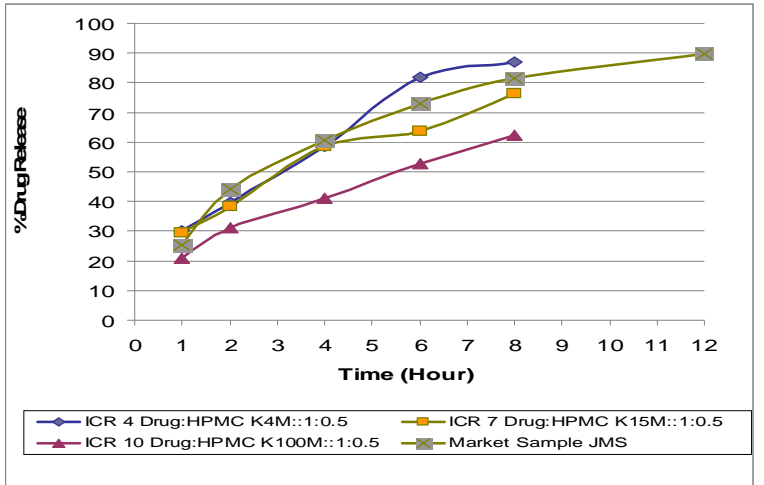

Figure 7. Dissolution profile of formulated products with different grades of HPMC at drug: polymer ratio 1:0.5.

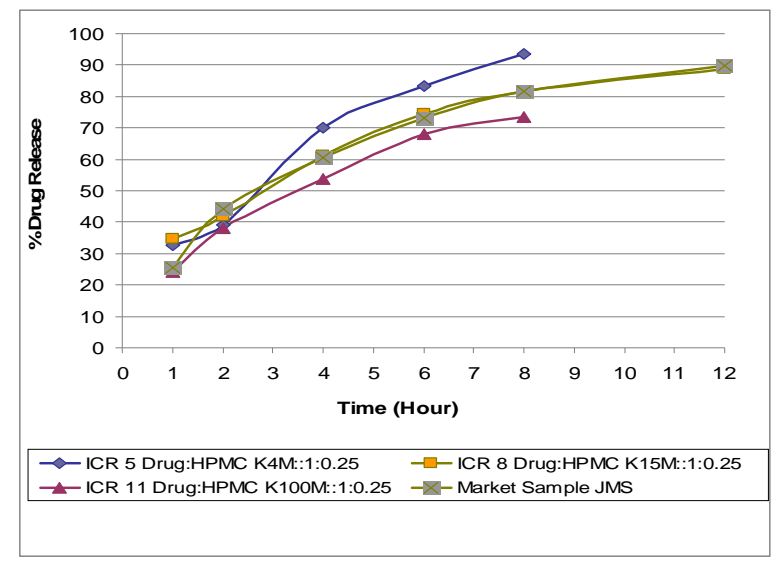

Figure 8. Dissolution profile of formulated products with different grades of HPMC at drug: polymer ratio 1:0.25.

\section{Drug Release Kinetics}

The release data of all the formulations were fitted into four different mathematical models namely zero order, first order, Higuchi model and Peppas model. The rate constants and $\mathrm{R}^{2}$ values for zero order, first order, Higuchi and "n" value for power law of all the formulated matrix tablets are given in Table 4. 
Table 4. Drug release kinetics of the formulated products.

\begin{tabular}{|c|c|c|c|c|c|c|c|}
\hline \multirow{2}{*}{$\begin{array}{l}\text { Formulation } \\
\text { Code }\end{array}$} & \multicolumn{2}{|l|}{ Zero order } & \multicolumn{2}{|c|}{ First order } & \multicolumn{2}{|c|}{ Higuchi model } & \multirow{2}{*}{$\begin{array}{r}\text { Peppas model } \\
\text { “n” Value }\end{array}$} \\
\hline & $\mathbf{K}_{0},\left(\% \mathrm{hr}^{-1}\right)$ & $\mathbf{R}^{2}$ & $\begin{array}{l}K_{r}, \\
\left(\% h^{-1}\right)\end{array}$ & $\mathbf{R}^{2}$ & $\begin{array}{l}K_{H} \\
\left(\% h^{-1}\right)\end{array}$ & $\mathbf{R}^{2}$ & \\
\hline ICR 1 & 47.14 & 0.9984 & 0.798 & 1.0000 & 59.93 & 0.7317 & 0.03 \\
\hline ICR 2 & 26.98 & 0.9224 & 0.317 & 0.8739 & 47.13 & 0.9207 & 0.28 \\
\hline ICR 3 & 9.22 & 0.9083 & 0.184 & 0.9139 & 22.35 & 0.9531 & 0.66 \\
\hline ICR 4 & 12.65 & 0.8521 & 0.157 & 0.9392 & 30.94 & 0.9738 & 0.57 \\
\hline ICR 5 & 13.55 & 0.8427 & 0.157 & 0.9183 & 33.18 & 0.9727 & 0.66 \\
\hline ICR 6 & 9.28 & 0.9244 & 0.177 & 0.9701 & 22.43 & 0.9431 & 0.70 \\
\hline ICR 7 & 11.04 & 0.7514 & 0.132 & 0.9163 & 27.32 & 0.9800 & 0.49 \\
\hline ICR 8 & 9.54 & 0.5470 & 0.086 & 0.8372 & 28.40 & 0.9254 & 0.49 \\
\hline ICR 9 & 7.52 & 0.8892 & 0.164 & 0.9543 & 18.30 & 0.9672 & 0.59 \\
\hline ICR 10 & 8.77 & 0.8282 & 0.147 & 0.9302 & 21.54 & 0.9941 & 0.50 \\
\hline ICR 11 & 10.85 & 0.8130 & 0.153 & 0.8828 & 26.66 & 0.9892 & 0.49 \\
\hline ICR 12 & 12.06 & 0.8999 & 0.174 & 0.9258 & 29.32 & 0.9775 & 0.61 \\
\hline ICR 13 & 11.89 & 0.8997 & 0.177 & 0.9112 & 28.90 & 0.9738 & 0.58 \\
\hline ICR 14 & 13.13 & 0.8896 & 0.170 & 0.9336 & 31.97 & 0.9753 & 0.65 \\
\hline ICR 15 & 12.75 & 0.9117 & 0.182 & 0.9257 & 30.92 & 0.9652 & 0.67 \\
\hline ICR 16 & 9.21 & 0.6543 & 0.105 & 0.7694 & 27.21 & 0.9591 & 0.45 \\
\hline ICR 17 & 9.09 & 0.6790 & 0.107 & 0.7786 & 26.78 & 0.9630 & 0.47 \\
\hline
\end{tabular}

Considering the correlation coefficient $\left(\mathrm{R}^{2}\right)$ values as obtained from the different kinetic equations, the drug release from most of the formulated matrix tablets were found to follow first order, higuchi kinetics and power law rather than zero order kinetic. The release exponent " $n$ " value for the different formulation ranged form 0.03 to 0.69 .

However, majority of the formulations (ICR 3, ICR 4, ICR 5, ICR 6, ICR 9, ICR 12, ICR 13, ICR 14 and ICR 15) showed the diffusional exponent; " $n$ " in between 0.5 and 1.0 which indicate the anomalous transport kinetics that means the drug is released by the combined mechanism of pure diffusion controlled and swelling controlled drug release. For formulations ICR 7, ICR 8, ICR 10 and ICR 11 "n" value was approximately 0.5 which indicated that drug was released by pure diffusion controlled mechanism (fickian diffusion). The remaining formulations, ICR 2, ICR 16 and ICR 17 showed " $n$ " value less than 0.5 . The smaller values of release exponent $(\mathrm{n}<0.5)$ may be due to drug diffusion partially through a swollen matrix and water filled pores in the formulations.

\section{Similarity Factor}

The similarity factor of formulated products with reference to marketed product is given in Table 5. The similarity factor of formulation ICR 16 (Drug:HPMC K15M:Mannitol::1:0.25:1) and ICR 17 (Drug:HPMC K15M:Mannitol::1:0.25:2) was 74.59 and 68.04 respectively (highest value among all formulations) which indicated that their dissolution profiles were most similar to marketed sample coded as JMS. 
Table 5. Similarity factor with reference to marketed sample JMS.

\begin{tabular}{|c|c|}
\hline Formulation Code & Similarity factor $\left(f_{s}\right)$ \\
\hline ICR 1 & 30.51 \\
\hline ICR 2 & 34.14 \\
\hline ICR 3 & 40.90 \\
\hline ICR 4 & 62.38 \\
\hline ICR 5 & 51.80 \\
\hline ICR 6 & 40.47 \\
\hline ICR 7 & 61.95 \\
\hline ICR 8 & 67.57 \\
\hline ICR 9 & 31.72 \\
\hline ICR 10 & 39.19 \\
\hline ICR 11 & 61.26 \\
\hline ICR 12 & 68.87 \\
\hline ICR 13 & 68.44 \\
\hline ICR 14 & 57.29 \\
\hline ICR 15 & 60.67 \\
\hline ICR 16 & 74.59 \\
\hline ICR 17 & 68.04 \\
\hline
\end{tabular}

\section{CONCLUSIONS}

The present study showed that the release of indomethacin depended on the percentage of polymer being used. It was observed that there was a linear relationship between the drug release and different viscosity grades of polymer. Thus we can infer that drug release profile decreases with increase in viscosity of polymer and, with increase polymer level in the formulations.

Among the three viscosity grades of HPMC used, HPMC K15M in concentration $6.25 \%$ w/w along with mannitol showed comparable release profile over 12 hours with respect to the release profile of one of the Indian marketed product.

Almost all formulations containing HPMC followed higuchi and peppas model.

In conclusion, $\mathrm{CR}$ tablets designed with a blend of an immediately releasing granules consisting of drug and disintegrant and a slow releasing matrix consisting of drug and polymer proved to be the way to deliver the drug like indomethacin (NSAID).

\section{ACKNOWLEDGEMENTS}

Authors are thankful to Mr. Jaya Bir Karmacharya, MFO, Omnica Laboratories Pvt. Ltd.

\section{REFERENCES}

1. Collett J, Moreton C. 2002. Modified-release Peroral dosage forms: Aulton ME , Pharmaceutics the science of dosage form design, $2^{\text {nd }}$ ed, Churchill Livinstone, London.

2. Weinberger M, Hendeles L 1996. Deriphylline in asthma, Review article. The New England Journal of Medicine. 334 (21):1380-1388.

3. Singh BN, Kim KH. 2002. Drug Delivery - Oral Route. Encyclopedia of Pharmaceutical Technology, 886-909.

4. M. N. V. Ravi Kumar, Neeraj Kumar 2001. Polymeric controlled drug delivery systems: Perspective issues and opportunities, Drug Development in Industrial. Pharmacy., 27: 130. 
5. Paulo Costa, Jose Manuel Sousa Lobo 2001. Modeling and comparison of dissolution profiles, European journal of pharmaceutical sciences, 13: 123-133

6. Mehta, Atul M Controlled release indomethacin United States Patent 4938968 http://www.freepatentsonline.com/4938968.html

7. Elkheshen SA 2001. Interaction of varapmil hydrochloride with carbopol 934P and its effect on the release rate of the drug and the water uptake of the polymer matrix, Drug development and industrial pharmacy 925-934. 